\title{
Prevalência do uso de protetor bucal por atletas dos principais clubes de futebol do estado do Rio de Janeiro
}

http://dx.doi.org/10.11606/1807-5509201800010033

\author{
Victor José BOTELHO* \\ Júlio CAL NETO* \\ Mônica CALASANS-MAIA* \\ Leonardo Santos ANTUNES \\ Lívia A. Alves ANTUNES* \\ José CALASANS-MAIA*
}

\section{Resumo}

Esportes de contato apresentam cada vez mais competividade e, com isso, há um aumento no número de lesões, em geral. Lesões orofaciais estão dentro desse aumento, principalmente traumatismos bucais e dentários. 0 protetor bucal é um aparato que diminui e/ou evita tais danos faciais. Dessa forma, o presente estudo objetivou verificar a prevalência e a importância do uso do protetor bucal nos atletas profissionais dos principais clubes de futebol do Estado do Rio de Janeiro. A amostra foi composta de 57 jogadores de futebol profissional entre 18 e 36 anos. A avaliação se deu através de questionário individual para cada atleta. Os resultados mostraram que $82,4 \%$ dos jogadores apresentaram lesões bucais. Além disso, $94,7 \%$ disseram ter conhecimento sobre protetores bucais e 76,7\% acharem seu uso necessário, porém apenas $12,2 \%$ responderam possuir algum protetor bucal. Conclui-se que apesar do conhecimento da importância do uso de proteção bucal, os atletas de futebol ainda não fazem uso de tal aparato de proteção.

PalavRas-Chave: Prevalência; Protetores Bucais; Traumatismos Dentários; Futebol.

\section{Introdução}

Com a ampliação na participação de atletas em esportes de contato e, por conseguinte, com o aumento da competitividade nessas atividades, observa-se um aumento nos relatos de lesóes orofaciais. Traumatismos em dentes e na face ocorrem frequentemente, principalmente, em esportes de contato ${ }^{1}$. As lesóes traumáticas nos esportes atingem alto índice, variando de acordo com o esporte praticado ${ }^{2}$.

As lesões mais comuns quando ocorrem traumatismos são: fraturas coronárias de esmalte e dentina, fraturas coronárias com exposição pulpar, e em alguns casos avulsóes dentárias, podendo acarretar em diversos casos a perda dos dentes envolvidos, atingindo principalmente os incisivos centrais superiores ${ }^{2}$.

A face é a parte do corpo mais exposta em esportes de contato. Lesóes dos tecidos moles ocorrem frequentemente. Abrasóes, contusóes e lacerações são comuns e devem ser avaliadas para descartar fraturas e ou lesão significativa ${ }^{3}$.
Protetores bucais demonstraram serem eficazes na redução do número e na severidade das lesóes traumáticas bucais que acometem atletas de esportes de contato ${ }^{4}$. Protegem os dentes, tecidos moles e outras estruturas, amortecendo e distribuindo a força de impacto. $\mathrm{Na}$ arcada superior, protege os tecidos moles e dentes anteriores; e na arcada inferior, evita contusóes mandibulares, deslocamentos e traumas na articulação temporomandibular ${ }^{5}$. As principais características de um protetor bucal são: ser feito com material resistente, deve recobrir todos os dentes e ter espessura oclusal adequada para não interferir na oclusão. Além disso, deve ser feito para alterar o mínimo possível a fala e a respiração. Existem três tipos de protetores bucais: os universais ou de estoque, os pré-fabricados e os feitos sob medida ${ }^{6}$.

Os universais ou de estoque são destinados a caber em qualquer boca e possuem pobre adaptação. As principais queixas são de que eles ficam soltos, são pesados, dificultam a fala e a respiração e requerem 
que o atleta fique de boca fechada para que fiquem no lugar. Às vezes são muito grossos nas superfícies oclusais e, geralmente, são muito finos na parte labial ${ }^{6}$. Tem como vantagem o baixo custo e a facilidade na aquisiçáo ${ }^{5}$.

Os pré-fabricados tem melhor adaptação dos que os de estoque, mas piores do que os feitos sob medida ${ }^{6}$. Estão disponíveis em duas versōes: os termoplásticos (boil and bite); ou os revestidos (shell-liner). Os termoplásticos são feitos a partir de uma moldeira termoplástica pré-formada de copolímero de PVAc - PE (EVA), ou PVC que, quando colocada em água quente, fica plastificada e então moldada na boca. Já os revestidos consistem em uma moldeira externa dura de cloreto de vinil que pode ser preenchida com uma camada de metil-metacrilato autopolimerizável ou silicone pelo usuário 5 .

Os protetores confeccionados sob medida são feitos a partir de uma impressão (moldagem) feita por um cirurgiáo dentista. Independentemente do material, estes dão melhor adaptação, volume e espessura $^{6}$. Geralmente, após obtenção do modelo em gesso da maxila do paciente, são produzidos

\section{Método}

\section{Amostra}

A amostra foi composta por 57 jogadores dos principais clubes de futebol do Estado do Rio de Janeiro, distribuídos da seguinte forma: 23 jogadores do Botafogo Futebol e Regatas, 20 jogadores do Clube de Regatas Flamengo e 14 jogadores do Clube de Regatas Vasco da Gama.

\section{Procedimentos éticos}

O Projeto de Pesquisa foi aprovado pelo Comitê de Ética em Pesquisa da Faculdade de Medicina/ Hospital Universitário Antônio Pedro (CEP CMM/ HUAP no 247/11; CAAE: 0260.0.258.000-11). Foi mantido contato com os departamentos os protetores através de em um aparelho a vácuo, sendo que os materiais mais usados são as placas de vinil termoplásticas. Esse tipo de material é mais confortável que os de outros tipos, pois se adaptam melhor, tem melhor retenção e distribuem melhor as forças de impacto, dando maior segurança ao usuário5.

A prevalência de traumatismo dentário varia dependendo do esporte, por exemplo, como dados encontrados em alguns estudos que obtiveram os seguintes resultados, respectivamente: variação na distribuição de traumas: judô $(22,3 \%-52,6 \%)$, basquete $(36,4 \%-70,6 \%)$, handball $(37,1 \%$ $57,1 \%)$ e futebol $(23,1 \%-39,3 \%)^{7,8}$. Outros estudos demonstraram que o futebol é um dos esportes de contato com maiores valores percentuais de traumatismo orofaciais, com variação de $11 \%$ a $32,3 \%$ do total de lesóes ${ }^{9,10}$. Além disso, mostrou-se que os jogadores de futebol ainda têm pouco conhecimento sobre a importância de protetores bucais ${ }^{10}$.

O objetivo deste trabalho foi avaliar, através de questionário individual, a prevalência do uso de protetor bucal e o conhecimento de sua importância para a prevenção de lesôes orofaciais, nos principais clubes de futebol do estado do Rio de Janeiro. odontológicos dos clubes envolvidos na pesquisa explicando o estudo e seus objetivos, esclarecendo dúvidas, obtendo permissão e colaboração.

\section{Instrumento para coleta de dados}

Um questionário com perguntas simples e objetivas foi desenvolvido pelos pesquisadores e foi distribuído ao departamento odontológico de cada clube para a realização da coleta de dados. Todos os dados foram obtidos de janeiro de 2011 a janeiro de 2012. A aplicação do questionário ficou a cargo dos cirurgiôes-dentistas de cada clube, uma vez que os clubes alegaram dificuldades de reunião de todo o grupo de atletas com o responsável pela realização da pesquisa. 


\section{Resultados}

O estudo demonstrou que a distribuição dos jogadores, segundo a idade, teve como média 23,26 anos, com o jogador mais jovem apresentando 18 anos e o mais velho 36 anos. Isso mostra que cada vez mais cedo os atletas tornam-se profissionais. É possível verificar na TABELA 1, o número de jogadores que sofreram alguma lesão ou traumatismo dentofacial durante a prática de futebol (ao longo de suas carreiras no esporte), separados também por times. Somente 10 jogadores dentre os 57 entrevistados, correspondendo ao total de $17,6 \%$.

TABELA 1 - Sofreu alguma lesão ou traumatismo dentofacial.

\begin{tabular}{lccc}
\hline Clube & Sim & Não & No jogadores \\
\hline Botafogo & $5(21,8 \%)$ & $18(78,2 \%)$ & 23 \\
Flamengo & $1(5 \%)$ & $19(95 \%)$ & 20 \\
Vasco & $4(28,6 \%)$ & $10(71,4 \%)$ & 14 \\
TOTAL & $10(17,6 \%)$ & $47(82,4 \%)$ & 57 \\
\hline
\end{tabular}

A FIGURA 1 demonstra os tipos de lesóes sofridas pelos jogadores dos respectivos clubes. Percebe-se que apenas laceraçōes intrabucais, dentes luxados e dentes fraturados foram citados, tendo o mesmo número de citaçóes (quatro).
Observa-se, na TABELA 2, o nível de conhecimento sobre o que são protetores bucais. Neste quesito podese perceber o alto nível de conhecimento dos jogadores com um percentual de $94,7 \%$ afirmando saber o que são protetores bucais.

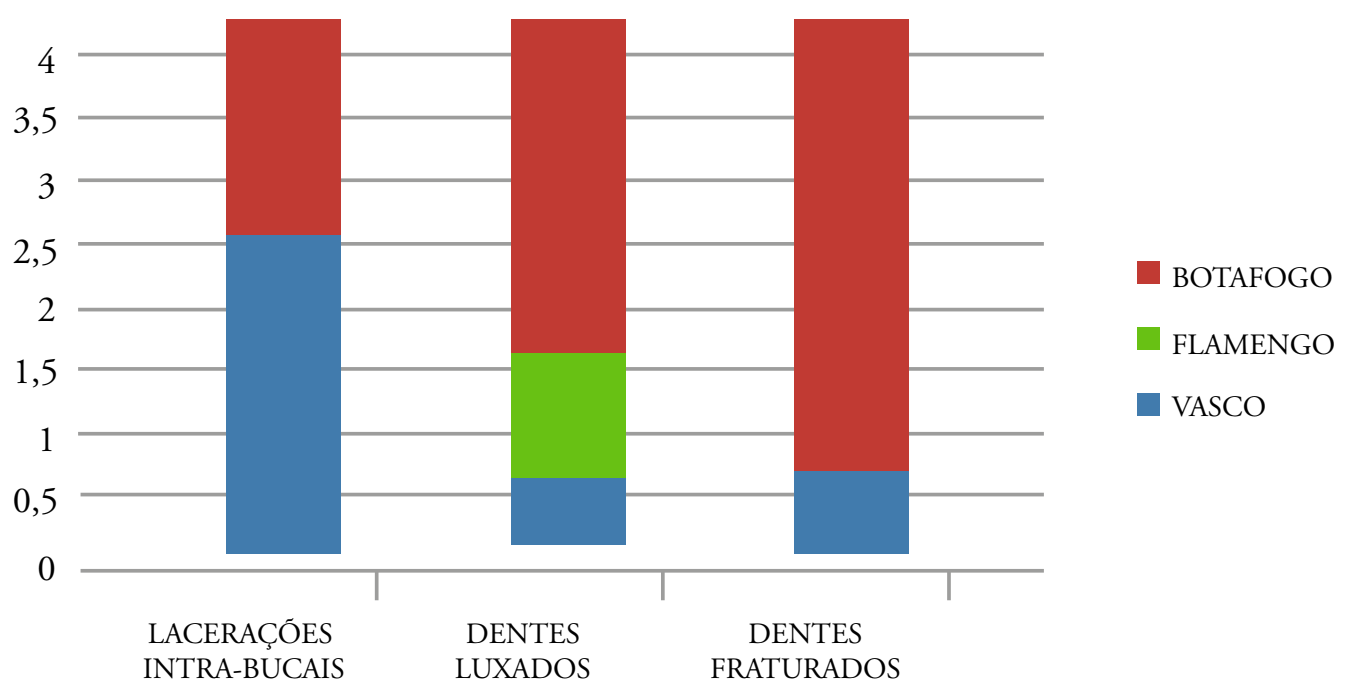

FIGURA 1 - Tipos de lesões citadas por clubes.

TABELA 2 - Conhecimento sobre o que são protetores bucais.

\begin{tabular}{lccc}
\hline Clube & Sim & Náo & No jogadores \\
\hline Botafogo & $23(100 \%)$ & 0 & 23 \\
Flamengo & $17(85 \%)$ & $3(15 \%)$ & 20 \\
Vasco & $14(100 \%)$ & 0 & 14 \\
TOTAL & $54(94,7 \%)$ & $3(5,3 \%)$ & 57 \\
\hline
\end{tabular}


A TABELA 3 mostra o número de jogadores que já receberam algum tipo de instruçáo sobre protetores bucais. Essa questão é mais profunda, implica se já receberam orientaçóes sobre como funcionam, qual sua finalidade, quais os tipos, quais as indicaçóes e como usar. Assim como o nível de conhecimento sobre o que são protetores bucais, o nível de instrução recebido sobre protetores bucais também demonstra um número alto com 48 jogadores $(84,2 \%)$ afirmando terem sido orientados quanto ao uso.

A TABELA 4 mostra se o jogador possui algum tipo de protetor bucal. Poucos jogadores possuem protetores bucais. Apenas 7 jogadores do total de 57 relataram possuir este dispositivo de segurança bucal.
Dentre os diversos tipos de protetores bucais disponíveis, foi percebido que nenhum jogador possui o protetor bucal de estoque, enquanto o protetor bucal feito sob medida pelo dentista foi o mais citado (FIGURA 2).

A TABELA 5 demonstra se o atleta considera o uso de protetor bucal necessário. Nota-se um número elevado de jogadores que acreditam que é importante o uso de protetor bucal em um total de 76,7\%. Curiosamente, um jogador do Botafogo FR respondeu não saber se é necessário ou não o uso de protetor bucal.

Na FIGURA 3, são apresentados os números de citaçóes de cada problema relacionado ao uso de protetor bucal.

TABELA 3 - Recebeu algum tipo de instrução sobre protetores bucais.

\begin{tabular}{lccc}
\hline Clube & Sim & Náo & No jogadores \\
\hline Botafogo & $18(78,2 \%)$ & $5(21,8 \%)$ & 23 \\
Flamengo & $19(95 \%)$ & $1(5 \%)$ & 20 \\
Vasco & $11(78,5 \%)$ & $3(21,5 \%)$ & 14 \\
TOTAL & $48(84,2 \%)$ & $9(15.8 \%)$ & 57 \\
\hline
\end{tabular}

TABELA 4 - Atleta possui algum tipo de protetor bucal.

\begin{tabular}{lccc}
\hline Clube & Sim & Não & No jogadores \\
\hline Botafogo & $3(13 \%)$ & $20(87 \%)$ & 23 \\
Flamengo & $2(10 \%)$ & $18(90 \%)$ & 20 \\
Vasco & $2(14,2 \%)$ & $12(85,8 \%)$ & 14 \\
TOTAL & $7(12,2 \%)$ & $50(87,8 \%)$ & 57 \\
\hline
\end{tabular}

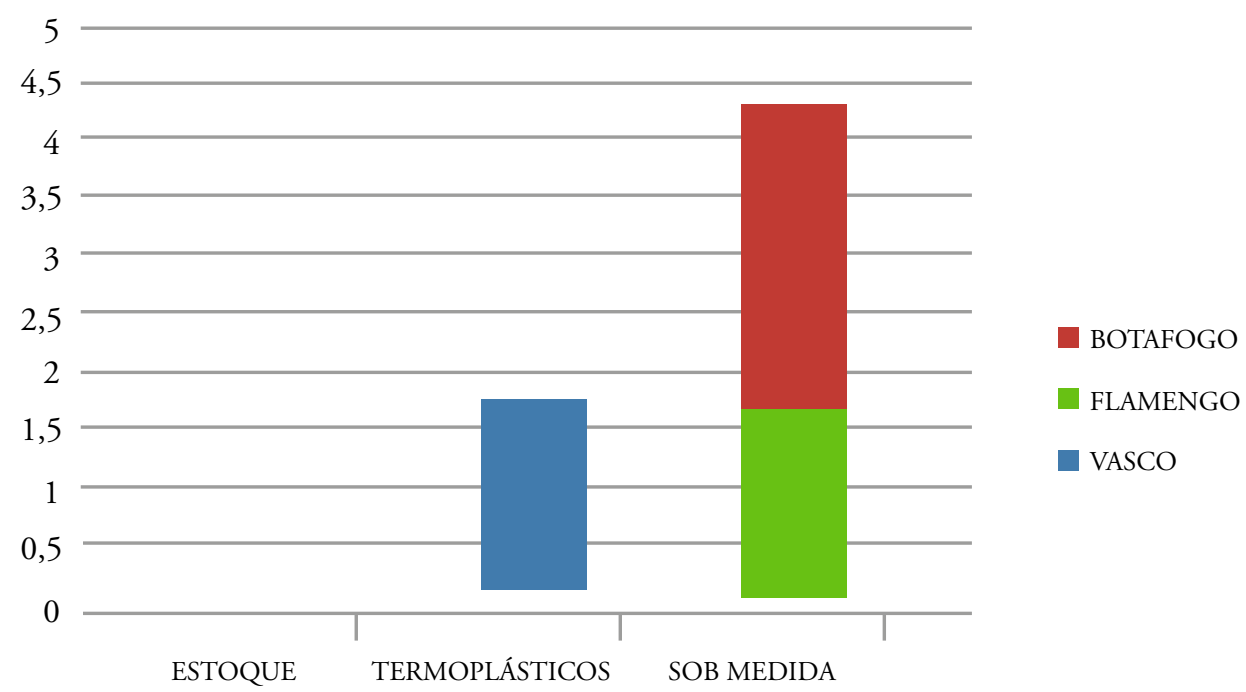

FIGURA 2 - Tipos de protetores bucais usados pelos jogadores entrevistados. 
TABELA 5 - Número de jogadores que considera o uso de proteção bucal necessária.

\begin{tabular}{lccc}
\hline Clube & Sim & Não & No jogadores \\
\hline Botafogo & $15(68,1 \%)$ & $7(31,9 \%)$ & 22 \\
Flamengo & $18(90 \%)$ & $2(10 \%)$ & 20 \\
Vasco & $10(71,4 \%)$ & $4(28,6 \%)$ & 14 \\
TOTAL & $43(76,7 \%)$ & $13(23,3 \%)$ & 56 \\
\hline
\end{tabular}

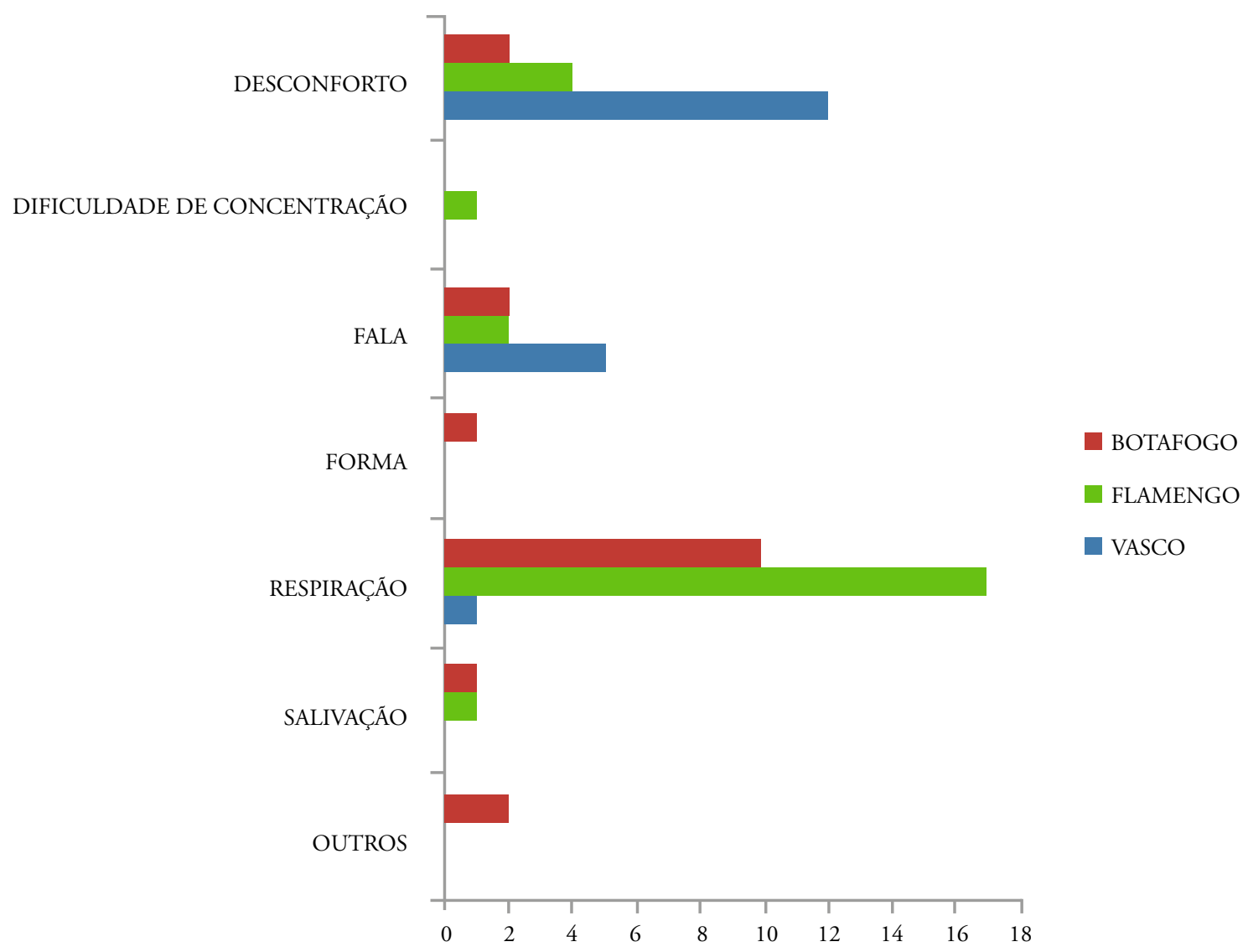

FIGURA 3 - Número de citações de cada problema no total.

\section{Discussão}

A proteção das estruturas orofaciais e, especialmente, dentárias nos esportes de contato é alvo de estudos que buscam o aprimoramento de técnicas, para com isso obter os menores índices de lesões possíveis ${ }^{5}$.

Diante dessa ótica, avaliou-se o conhecimento sobre protetores bucais e o seu uso em 57 atletas profissionais dos 3 seguintes clubes do Rio de Janeiro: Botafogo FR, CR Flamengo e CR Vasco da Gama. Contudo, deve-se ressaltar que o estudo tinha a intenção de abranger ainda mais clubes do estado do Rio de Janeiro, porém alguns clubes não aceitaram participar do estudo. Importante dizer que os que participaram da pesquisa tinham cirurgião-dentista ou equipe odontológica no clube, e, quanto melhor a estrutura do clube, mais fácil foi o acesso.

Os clubes que aceitaram participar do estudo fizeram algumas ressalvas quanto como seria feito a pesquisa. A princípio, o modo que seria feito a abordagem com os jogadores era através de uma reuniáo com todos onde seria explicado o questionário, distribuindo o Termo de Consentimento Livre e Esclarecido (TCLE) e que fosse tudo respondido no mesmo momento. Porém os clubes disseram não ser possível este modo de abordagem e propuseram que 
fossem deixados os questionários para que a medida que cada jogador que fosse ao departamento médico ou odontológico, este seria avaliado, preenchido o questionário e assinado o TCLE.

Com os questionários preenchidos, deu-se início aos levantamentos. Foram entrevistados 57 jogadores. O jogador com menor idade tinha 18 anos e o mais velho 36 anos. Média de idade de 23,26 anos. O Botafogo FR foi o clube com o maior número de jogadores que responderam os questionários, enquanto o CR Vasco da Gama foi o clube com menor número de jogadores.

A presente pesquisa teve como foco toda a carreira do atleta durante a prática de futebol profissional. A incidência de lesóes ou traumas dentofaciais foi baixa com apenas 10 jogadores $(17,6 \%)$ respondendo terem sofrido algum traumatismo bucal. Números maiores foram encontrados em outros estudos, com achados de $23,1 \%$ e $39,3 \%$, respectivamente ${ }^{7,8}$.

Os tipos de lesóes ou traumas mais citados foram: laceraçôes intrabucais, dentes luxados e dentes fraturados, o que corrobora com outro estudo que concluiu que laceraçóes é o tipo mais frequente de injúria encontrada no futebol ${ }^{10}$. Outro achado mostra que dentes fraturados $(74,1 \%)$ e avulsōes dentárias (59,3\%) foram os tipos de injúrias dentárias mais citadas durante a prática futebolística ${ }^{11}$. Ainda sobre traumatismo dentário, outro estudo concluiu que fraturas de esmalte $(48,6 \%)$ e fraturas não complicadas de esmalte-dentina $(17,1 \%)$ tiveram a maior prevalência ${ }^{12}$.

No que diz respeito ao nível de conhecimento sobre o que são protetores bucais e se já recebeu algum tipo de instrução sobre os mesmos, todos demonstraram valores percentuais altos de $94,7 \%$ e $84,2 \%$ respectivamente, o que pode ser explicado pela existência de cirurgióesdentistas nos clubes. Essa avaliaçáo foi diferente de uma pesquisa feita no Japão, onde o percentual do nível de conhecimento era de apenas $27,1 \%{ }^{10}$. A consciência da necessidade de protetores bucais foi maior em atletas de esportes de contato $(67,5 \%)$ como demonstrado em um estudo na Índia ${ }^{13}$.

Em outro estudo realizado no Japão, evidenciouse que $81,8 \%$ dos atletas de futebol acreditavam que o uso do protetor bucal era desnecessário e a maioria dos jogadores de rugby $(73,8 \%)$ acreditavam ser necessário ${ }^{10}$. Estudo na Turquia demonstrou que $48 \%$ também acreditavam que o uso do protetor bucal era desnecessário ${ }^{12}$. No presente estudo, nesta mesma avaliação, do total de jogadores, $76,7 \%$ consideraram o uso do protetor bucal necessário.

No entanto, no presente estudo, apesar da maioria dos jogadores acreditarem que o uso de protetor bucal é necessário e saber de sua importância, somente $12,2 \%$ dos jogadores informou usar esse dispositivo bucal de proteção. Outras pesquisas tiveram resultados ainda menores $(0,8 \% \text { e } 0,29 \% \text {, respectivamente })^{10,12}$.

Neste estudo, dos 7 jogadores que possuíam protetores bucais, 5 deles usavam protetores feitos sob medida (confeccionados por um dentista). A curiosidade ficou em torno do CR Vasco da Gama, onde 2 atletas disseram possuir e usar protetor bucal, mas não os feitos pelo dentista, mesmo tendo um cirurgião-dentista no clube. $\mathrm{O}$ baixo número de jogadores usuários pode ser explicado pelos problemas relacionados ao seu uso, relatados pelos atletas. Respiração, fala e desconforto foram os problemas mais citados pelos jogadores. Esse resultado é semelhante ao encontrado em uma pesquisa no Brasil, que observou como principal fator de resistência ao uso, a dificuldade de respiração que está relacionado a adaptação e retenção do protetor bucal à arcada dentária 5 . Também é semelhante a dados na Turquia, onde problemas de comunicação e respiratórios foram mais citados ${ }^{12}$. Porém, outro estudo demonstrou resultados diferentes: a razão mais frequente relatada, por atletas de esportes de contato, foi a percepção de redução na performance atlética, com $28,9 \%$. Nos praticantes de esportes sem contato, foi que o uso do protetor bucal não era obrigatório $(55,2 \%)^{13}$.

Como pontos positivos do estudo pode-se citar que, apesar de saber que seria complicado a realizaçáo do estudo, os clubes tiveram boa abertura para a realizaçáo do trabalho em especial o Botafogo FR. Além disso, algumas perguntas que se esperavam respostas negativas (exemplo: se tiveram alguma instrução e se achavam necessário o uso de protetores bucais), tiveram respostas bastante positivas. A amostra foi constituída de profissionais do futebol de alto nível e reconhecimento sendo esses dados de alta relevância. Durante a pesquisa, notou-se que a odontologia ainda é um campo da saúde deixada de lado pelos clubes. Os cirurgióes-dentistas dos clubes declararam a dificuldade e a resistência de mostrar a importância que a saúde bucal têm sobre a saúde total dos atletas, aos presidentes dos clubes. Mas aos poucos, essas questóes estão mudando e alguns clubes já começaram a notar a importância da Odontologia Esportiva.

Em contrapartida como ponto negativo está: não ter os dados dos demais clubes, pois estes não aceitaram participar da pesquisa. O estudo teve também uma amostra mais reduzida, pois nem todos os jogadores das equipes quiseram responder o questionário. 
Os dados do presente estudo devem ser analisados com cautela por se tratarem de dados preliminares. Além disso, sugere-se a continuidade da pesquisa com maior amostra, com outros esportes sendo relacionados e até outras categorias dentro do mesmo esporte (por exemplo: juniores, infantil).

\section{Abstract}

\section{Prevalence of mouthguard use by athletes of the main soccer clubs of Rio de Janeiro state}

Contact sports have increasingly competitiveness and, therefore, there is na increase in the number of injuries in general. Orofacial injuries are within of this increase, mainly buccal and dental trauma. The mouthguard is an apparatus that reduces and/or prevents such facial injuries. Thus, the present study aimed to determine the prevalence and the importance of using the mouthguard in professional athletes of the top soccer clubs of Rio de Janeiro State. The sample consisted of 57 professional soccer players between 18 and 36 years. The evaluation was made through individual questionnaire for each athlete. The results showed that $82.4 \%$ of subjects showed oral lesions. In addition, $94.7 \%$ said they had knowledge of mouthguards and $76.7 \%$ deem their use necessary, but only $12.2 \%$ said having some mouth guard. In conclusion, despite the knowledge of the importance of using oral protection, soccer players still do not use such protection apparatus.

\section{KeYwords: Prevalence; Mouth Protectors; Tooth Injuries; Soccer.}

\section{Referências}

1. Canto GL, Oliveira J, Hayasaki SM, Cardoso M. Protetores bucais: uma necessidade dos novos tempos. Rev Dent Ortoped Facial. 1999;6:20-6.

2. Andreasen JO, Andreasen FM. Texto e atlas colorido de traumatismo dental. Porto Alegre: Artmed Editora; 2001.

3. Crow RW. Diagnosis and management of sports-related injuries to the face. Dent Clin North Am. 1991;35(4):719-32.

4. Yamada T, Sawaki Y, Ueda M. Mouth guard for athletes during orthodontic treatment. Endod Dent Traumatol. 1997;13:40-41.

5. Barberini AF, Aun CE, Caldeira CL. Incidência de injúrias orofaciais e utilização de protetores bucais em diversos esportes de contato. Rev Odontol UNICID. 2002;14(1):7-14.

6. Heintz WD. Maximum mouth protector for contact sports. J Prosthet Dent. 1959;9(11):874-880.

7. Ferrari $\mathrm{CH}$, Medeiros JMF. Dental trauma and level of information: mouthguard use in different contact sports. Dent Traumatol. 2002;18:231-6.

8. Andrade RA, Evans PL, Almeida AL, Silva JJR, Guedes AML, Guedes FR, et al. Prevalence of dental trauma in Pan American games athletes. Dent Traumatol. 2010;26(3):248-53.

9. Diab N, Mourino AP. Parental attitudes toward mouthguards. Am Acad Pediatr Dent. 1997;19(8):455-460.

10. Yamada T, Sawaki Y, Tomida S, Tohnai I, Ueda M. Oral injury and mouthguard usage by athletes in Japan. Endod Dent Traumatol. 1998; 14(2):84-87.

11. Correa MB, Schuch HS, Collares K, Torriani DD, Hallal PC, Demarco FF. Survey analysis on the occurrence of dental and preventive strategies among professional Brazilian soccer players. J Appl Oral Sci. 2010;18(6):572-6.

12. Uzel I, Aykut-Yetkiner A, Ersin N, Ertugrul F, Oncag O, Attin R. Dental trauma and mouthguard usage among soccer players in Izmir, Turkey. Dent J. 2014;2:78-84.

13. Tiwari V, Saxena V, Tiwari U, Singh A, Jain M, Goud S. Dental trauma and mouthguard awareness and use among contact and noncontact athletes in central India. J Oral Sci. 2014;56(4):239-243.
ENDEREÇO
Victor José Botelho
Universidade Federal Fluminense
Recebido para publicação: 20/12/2015
Rua Mario Santos Braga, s/n
24220.900 - Niterói - RJ - BRASIL
e-mail: victorjo@globo.com
1a. Revisão: 19/02/2016
2a. Revisão: 21/03/2016
Aceito: 23/03/2016 
